\title{
La metáfora biológica en la obra de Manuel González Prada
}

\section{The biological metaphor in the work of Manuel Gonzalez Prada}

\author{
Camilo Rubén Fernández-Cozman \\ Universidad de Lima \\ crferna@ulima.edu.pe
}

\begin{abstract}
Manuel González Prada is one of the most important Latin American authors. He used the biological metaphor to criticize Peruvian society in the late nineteenth century. The metaphor of disease, animal and plant are three kinds of analog procedures that González Prada uses according to a naturalistic vision, heiress of Spencer's evolutionism. González Prada questions the imitation and lack of stylistic precision of writers in the nineteenth century, as well as conceiving that Peru is a sick organism.
\end{abstract}

Keywords: metaphor, biological, disease, naturalistic, vision

Poeta, teórico del verso, ensayista, orador y político peruano, Manuel González Prada (1844-1918) fue uno de los grandes pensadores latinoamericanos porque renovó la prosa ensayística para hacer un retrato de la sociedad peruana de finales del siglo XIX. También modernizó el verso incorporando los aportes de poetas parnasianos franceses y fue precursor del indigenismo y del modernismo de Rubén Darío, poeta nicaragüense que inició la emancipación de América Latina respecto de la poesía española que había sido imitada por los poetas latinoamericanos durante gran parte del siglo XIX.

La crítica especializada ha puesto de relieve el estudio de la biografía de González Prada y el papel de este intelectual en la modernización de la poesía peruana en su labor como teórico del verso y poeta que experimentó con nuevas estrofas 
europeas como el triolet francés o la balada alemana (Fernández Cozman, 2005; Lino, 2013). Los investigadores han abordado algunos aspectos del pensamiento de González Prada destacando el sincretismo presente en este último, así como su visión del indio y de la cultura peruana (García Salvatecci, 1972, 1990; Sobrevilla, 2005, 2012; Podestá, 1975; Tauzin-Castellanos, 2006; Ward, 2001).

Sobre la base de los aportes de García Salvatecci (1972), Sobrevilla (2012) señala cuatro etapas en el pensamiento de Manuel González Prada: 1) el período de los años en formación (1844-1879); 2) la etapa radical-positivista (1879-1891); 3) la fase europea (1891-1898) y 4) el período radical-anarquista (1898-1918). Los dos momentos más importantes son el segundo y el cuarto porque implican una modernización del ensayo como género en el Perú. La defensa del indígena y el interés por el mundo andino aparecen en el célebre "Discurso en el Politeama" de 1888, donde González Prada afirma que el verdadero Perú se halla constituido no por criollos, sino, sobre todo, por los indios. En otras palabras, aboga por un Perú de matriz indígena. En Pájinas ${ }^{1}$ libres (que recoge discursos de su etapa radical-positivista y fue publicado en 1894) González Prada (2015) cree que el problema indígena es de carácter ético, pues hay en nuestro país una crisis de valores morales en todos los órdenes de la vida social y en las clases dominantes; por el contrario, en Horas de lucha (que compila textos de su período radical-anarquista y vio la luz en 1908), el escritor subraya (González Prada, 2015) que el problema indígena es de carácter económico, pero que los indígenas deben liberarse por ellos mismos (Sobrevilla, 2005). Nuestro autor fundó el partido Unión Nacional en 1891, pero cuando se acercó al anarquismo rompió con la Unión Nacional, en 1902, porque, en aquel entonces, dicha organización política se aproximó al gobierno de Eduardo López de Romaña (1899-1903).

En nuestro artículo, primero, nos referiremos escuetamente el desarrollo del positivismo en Latinoamérica porque no se comprende plenamente la metáfora biológica sin el desarrollo de dicha corriente del pensamiento. Luego nos centraremos en el análisis de la metáfora biológica en la ensayística de González Prada. Pondremos de relieve algunos discursos que pronunció este célebre pensador porque él fue un gran orador que denunció la corrupción en las clases dominantes y anticipó la crisis ética de los gobernantes en el siglo XX, aspecto que no ha sido superado aún en las sociedades latinoamericanas de hoy. Nuestro propósito principal es abordar el funcionamiento de la metáfora biológica en los ensayos de González Prada, hecho que le permite a este reflexionar sobre la crisis de la sociedad y la cultura peruanas a finales del siglo XIX, es decir, después de la guerra de Perú y Chile que se produjo entre 1879 y 1883.

\footnotetext{
${ }^{1}$ González Prada escribió, como título del libro, Pájinas libres y no Páginas libres. Así se enfrentó a la normativa castellana dictaminada por la Real Academia Española. En muchas ocasiones, reemplazó la "y" por la "i”", por ejemplo, en "Propaganda i ataque", texto que analizaremos más adelante.
} 
Quintanilla (2006, p. 66) considera que el positivismo bebió de varias tradiciones:

A grandes rasgos, podría decirse que el desarrollo de las ciencias naturales durante los siglos XVII y XVIII, así como el auge del empirismo británico y, en general, del proyecto cartesiano moderno de una Mathesis Universalis, condujo a algunos filósofos modernos a la convicción de que finalmente habíamos desterrado el mito y la superstición, representados por la metafísica y la teología, para acceder a la época de la supremacía de la ciencia, del discurso riguroso y legítimo, así como de un sostenido progreso hacia una mayor racionalidad en la vida social.

En Latinoamérica, uno de los que incorporaron el positivismo fue el pensador argentino Domingo Faustino Sarmiento (1811-1888) con Facundo o civilización y barbarie, que vio la luz en 1845, y donde se identificaba el progreso con lo urbano y lo europeo. En México, Gabino Barreda (1818-1881), discípulo de Comte entre 1849 y 1851, reflexionó sobre la educación a través de las propuestas positivistas (Quintanilla, 2006). En Perú, fue González Prada uno de los que introdujo el positivismo y lo hizo a través del empleo de la metáfora biológica en sus discursos, a la vez que enfatizó la ciencia como pilar del desarrollo social de una nación.

En la crítica literaria peruana, hay dos importantes representantes del positivismo en el siglo XX: José de la Riva Agüero (1885-1944) y Luis Alberto Sánchez (1900-1994). El primero, en Carácter de la literatura del Perú independiente (Riva Agüero, 1962; texto publicado en 1905), consideraba que la literatura peruana formaba parte de la española, como la de Aragón o de Murcia; además, pensaba que las sociedades llamadas "inferiores" debían imitar necesariamente a las civilizadas (por ejemplo, la francesa) sobre la base de una visión lineal de la historia. Sánchez comenzó su labor en la segunda década del siglo XX; sin embargo, su obra La literatura peruana (1975), "es un curioso fruto tardío del positivismo decimonónico. Asimilando algunos planteamientos de Taine, Sánchez estructura sus parámetros en torno a los conceptos de Hombre y Medio" (García Bedoya Maguiña, 2004, p. 17). A diferencia de Riva Agüero y de Sánchez, González Prada se interesó en la crisis moral del Perú contemporáneo, de finales del siglo XIX e inicios del XX. Después de una caracterización de la metáfora biológica, analizaremos tres discursos de González Prada que abarcan desde 1886 a 1888 y son representativos de su interés por denunciar tanto la falta de valores éticos en las clases dominantes como la carencia de originalidad en los escritores peruanos de aquella época.

\section{HACIA UN INTENTO DE DEFINICIÓN DE LA METÁFORA BIOLÓGICA}

Como dicen Lakoff \& Johnson (2003), nuestro pensamiento es, en gran medida, de carácter metafórico. Concebimos el mundo y dirigimos nuestros actos a partir de ciertas metáforas. De allí que uno de sus libros más importantes se denomine 
Metaphors We Live By, y en dicho título se observa cómo vivimos a través de las metáforas. Cuando hablamos de las metáforas biológicas, nos referimos a aquellas que se manifiestan en el funcionamiento de ciertos órganos o la presencia de un imaginario vegetal o animal. Por ejemplo, en la metáfora "la vida es la respiración del aire fresco de la libertad" el vivir se asocia con el ejercicio del acto de respirar de modo independiente y sin el control de los grupos hegemónicos de una sociedad. Otro caso es "las personas son plantas" (Lakoff \& Turner, 1989), donde los seres humanos son concebidos como robles o cedros según el contexto que encauza la interpretación del enunciado. Asimismo, los sujetos pueden ser imaginados a partir de las figuras de animales; verbigracia, "ese hombre es un tigre", procedimiento metafórico que implica vincular la isotopía de lo humano (Greimas, 1987) con la de lo animal tomando en cuenta la inteligencia y capacidad para cazar del felino en relación con la del ser humano.

\section{LA METÁFORA BIOLÓGICA EN “CONFERENCIA EN EL ATENEO DE LIMA" (1886)}

Esta es la primera conferencia importante de González Prada ofrecida en el célebre Ateneo de Lima y se sitúa en la fase radical-positivista de nuestro autor. Comienza con una metáfora biológica, heredera del evolucionismo de Herbert Spencer:

Los hombres de genio son cordilleras: con sus deshielos de Verano producen hilos de agua destinados a convertirse en lagos que retratan la cúpula de los cielos o en ríos que hacen retroceder las olas del océano. Tal cual riachuelo desbordado forma lagunas y charcas en que chapotean ranacuajos y sapos: estos sapos y ranacuajos son los malos imitadores (González Prada, 2009, p. 15).

Aquí observamos cómo la visión naturalista (Tauzin-Castellanos, 2009) de González Prada hace que la teoría de los estados de la materia sirva para explicar la dimensión imponente de los genios del arte y de la literatura. Es decir, los cambios en la naturaleza (de lo sólido a lo líquido, por ejemplo) permiten explicitar con precisión las transformaciones de la vida social y cultural. En tal sentido, la metáfora $a$ es $b$ (los genios son cordilleras) establece una jerarquía y tiene una determinada dimensión orientacional (Lakoff \& Johnson, 2003²). Por ello, los genios se sitúan en

\footnotetext{
${ }^{2}$ Lakoff \& Johnson (2003) clasifican las metáforas en orientacionales (“caí en una severa depresión", procedimiento figurativo que sitúa espacialmente esta última respecto de la oposición arribaabajo), estructurales ("la vida es sueño", analogía que configura un concepto abstracto en relación con el otro al concebir que la existencia humana es sinónimo de una experiencia onírica interminable) y ontológicas ("la mente es una máquina", enunciado que implica cuantificar un concepto abstracto al enfatizar que el pensamiento es calibrado a través de términos tecnológicos).
} 
la parte de arriba; en cambio, los imitadores están en el ámbito de abajo. Sin embargo, hay una especie de herencia, transmitida de maestro a discípulo, que enlaza a los primeros con los segundos. Se trata, sin duda, del "riachuelo desbordado" que representa metafóricamente la ingente creación literaria de los genios. Entonces entra a tallar la metáfora animal: los malos imitadores son sapos y ranacuajos $^{3}$, vale decir, autores de dimensión baladí frente a las cordilleras que son los grandes creadores. Asimismo, las metáforas poseen un cariz argumentativo indiscutible (Perelman \& Olbrechst-Tyteca, 1989), pues sirven para fundamentar las ideas y no solo constituyen meros recursos formales. En el fragmento de González Prada antes citado, observamos el argumento de la dirección que se manifiesta cuando "es posible descomponer la prosecución de un fin en varias etapas y examinar la manera en que se transforma la situación" (Perelman \& Olbrechst-Tyteca, 1989, p. 434). Existen, por eso, tres etapas: la primera es la del deshielo que implica una transformación de la materia (de lo sólido a lo líquido); la segunda es la conversión del estado líquido en un riachuelo; y la tercera es la aparición de sapos y ranacuajos que juegan en las charcas y las lagunas formadas por el mencionado riachuelo.

Sin duda, los grandes creadores, para González Prada, son Homero, Virgilio, Sófocles y Eurípides, entre otros. Asimismo, el escritor concibe al Perú como un organismo vivo que solamente se ha dedicado a imitar ciegamente la producción literaria de otros países: "En Literatura, como en todo lo bueno y lo malo, el Perú ha vivido de la imitación. Hemos imitado a Quintana, Espronceda, Zorrilla, Campoamor, Trueba, y seguimos la serie de imitaciones imitando a Heine y Bécquer" (González Prada, 2009, p. 15). Uno de los casos más representativos es la imitación que los escritores peruanos han realizado del español José Selgas, a quien critica González Prada y para ello emplea otra metáfora animal:

Nunca va [Selgas] en línea recta hacia el asunto, sino forma curvas y ángulos, y retorciéndose y ovillándose como ciertos animales invertebrados; de modo que, cuando nos le figuramos muy lejos de nosotros, está haciendo cabriolas a nuestras espaldas. Como personaje de comedia mágica, se pierde en las nubes, y de repente asoma por un escotillón. Selgas, en fin, sube a la cuerda floja, da saltos mortales, realiza prodigios de agilidad; pero, de cuando en cuando, pierde el equilibrio, suelta la vara, y cae sobre los espectadores (González Prada, 2009, p. 17-18).

En este caso se observa cómo González Prada traza una homología entre el mundo natural y el social. Aquello que se manifiesta en la naturaleza, también se revela en el dominio de la cultura. He ahí la analogía: algunos animales invertebrados se ovillan y retuercen; del mismo modo, Selgas no tiene capacidad de síntesis, sino que emplea un estilo retorcido, alambicado y exento de precisión. Aquí aparece un principio científico fundamental de la geometría euclidiana: la línea recta es la más

\footnotetext{
3 "Ranacuajo" es un arcaísmo de "renacuajo".
} 
corta entre dos puntos. Frente a esta línea recta, la curva implica un camino más largo y constituye, además, sinónimo de redundancia en el ámbito del estilo literario. En tal sentido, Selgas cae en dicho yerro y desdeña la economía del lenguaje. Vale la pena recordar que Spencer (2017), con Filosofía del estilo (libro publicado en 1852), fue uno de los pensadores decimonónicos más influyentes en la época de González Prada y se refirió de manera detenida a la economía en el uso de las palabras, de las oraciones y figuras retóricas. En otras palabras, el escritor, según Spencer, no debería emplear vocablos de más, ni abusar de recursos estilísticos que afecten la legibilidad de los enunciados.

Posteriormente, González Prada emplea, en el fragmento arriba citado, la alegoría barroca de que la vida es un teatro, tan cara a Pedro Calderón de la Barca (2018), de El gran teatro del mundo, donde se plantea la idea de que cada uno cumple el papel de cierto actor en la vida, como si esta fuera una obra teatral. Selgas pasa a ser un personaje de comedia, es decir, desempeña un determinado rol en el mundo. Claro está que, en el ensayo de González Prada, no aparece la figura de la divinidad tal como en la obra de Calderón. Pero llama la atención la idea de que Selgas semeje un artista circense que aparenta ser un prodigio en el campo literario, mas luego los espectadores observan que todo lo realizado por él fue, en realidad, una farsa. En consecuencia, la crítica de González Prada a Selgas subraya la falta de autenticidad de este último, pues los recursos artísticos del escritor español parecen tener un alto grado de perfección; pero, en verdad, revelan ineficacia y torpeza. Al final, Selgas cae estrepitosamente sobre el público. Ello conduce metafóricamente a la conclusión de que Selgas no es un gran escritor, sino solamente un embaucador en el ámbito del lenguaje literario. Por ende, González Prada (2009, p. 17) utiliza la metáfora de la enfermedad al afirmar que Selgas: "En el estilo, asmático entre los asmáticos, fatiga con los retruécanos, aburre con la antítesis, desconcierta con el rebuscamiento". En otras palabras, hay aquí una percepción antitética: tener un buen estilo es sinónimo de estar sano; en cambio, no poseer destreza estilística es síntoma del padecimiento de una determinada enfermedad. Esta concepción se asocia nuevamente con la visión organicista de Spencer, analizada por Bruno Podestá (1975) en el pensamiento de González Prada.

En la conferencia en el Ateneo de Lima, González Prada llega a utilizar simultáneamente la metáfora vegetal, la animal y la de la enfermedad:

Las rocas producen liquen porque no pueden alimentar el cedro. Los que gozamos con la prosa y el verso de los maestros, somos capaces de alimentarnos con médula de leones; ¿por qué someternos a dieta medida, al régimen de los dispépticos? Si las naciones de Europa son los paquidermos del reino intelectual, no seamos en el Perú, los microbios de la Literatura (González Prada, 2009, p. 25).

Las rocas representan a los escritores desprovistos de sensibilidad artística que son incapaces de dar su aporte a la tradición literaria que se halla representada en el 
cedro. Asimismo, los buenos lectores se pueden alimentar de la médula de los leones que son los grandes escritores. En consecuencia, no tiene sentido ni la dieta (la exigua lectura de obras magistrales) ni el régimen alimenticio de las personas que padecen dispepsia (metáfora de la enfermedad gástrica). La conclusión final subraya cómo la grandeza de un paquidermo (un autor europeo de longeva tradición) se contrasta con el carácter minúsculo de un peruano que se complace en imitar ciegamente los aportes de los autores de otras tradiciones literarias más prestigiosas. En ese sentido, la metáfora biológica se sostiene en la idea de que leer es deglutir (vale decir, alimentarse intelectualmente) el contenido de obras literarias. Por eso, los animales más grandes (los paquidermos como los elefantes o jabalíes, verbigracia) representan a los fundadores de la tradición literaria; en cambio, los seres más pequeños como los microorganismos (el bacilo de Koch, por ejemplo) personifican, en el Perú, a los autores sin trascendencia alguna en el ámbito de la tradición literaria.

González Prada defiende la prosa no alambicada y, para ello, utiliza otra vez la metáfora animal a partir de la isotopía del movimiento y la comparación entre un mamífero y un reptil: "Entre la prosa que se agita con vertiginoso revoloteo de murciélago y la que se mueve con insoportable lentitud de serpiente amodorrada, existe la prosa natural" (2009, p. 27). Las manifestaciones de esta última, según González Prada, están en El Lazarillo de Tormes y en Don Quijote; pero también, en los grandes autores clásicos griegos. Sin embargo, el escritor peruano emplea nuevamente la metáfora vegetal para subrayar la conveniencia de evitar la vana retórica y de buscar la tan ansiada precisión conceptual; pues hay que despojarse "de aquella mala tendencia que nos induce a preferir el follaje de las palabras al fruto de las ideas" (González Prada 2009, p. 29). Por ello, el poeta es, en realidad, un árbol que se arraiga en el suelo, pero que vuela con la imaginación hacia las nubes y, en consecuencia, remite a la noción de árbol aéreo del cual habla Bachelard (1992) porque manifiesta una vida dinámica al elevarse desde la tierra hacia el cielo: "Sí: el poeta legítimo [...] personifica al árbol arraigado en la cumbre de un monte: por las ramas, que forman la imaginación, pertenece a las nubes: por las raíces, que constituyen los afectos, se liga con el suelo" (González Prada, 2009, p. 30).

En suma, en la conferencia en el Ateneo de Lima, González Prada considera que si bien el Perú se había liberado de España en 1821, no había logrado una verdadera emancipación intelectual. Para ello, los escritores peruanos deberían asimilar creativamente los aportes de las literaturas europeas, pero sin caer en la mera imitación. Se trata de emplear el neologismo y el provincialismo (voces tomadas de las lenguas aborígenes, por ejemplo), mas de manera cautelosa. Además, para González Prada, "las Matemáticas, las Ciencias Naturales y la Industria nada envidian a los siglos pasados [...]; lo único infalible, la Ciencia, lo único inviolable, la verdad" (2009, p. 29). En otras palabras, el autor manifiesta una fe inquebrantable en el pensamiento científico para lograr el progreso de una nación. 


\section{LA METÁFORA DE LA ENFERMEDAD EN "DISCURSO EN EL POLITEAMA" (1888)}

Este discurso de González Prada fue leído en el teatro Politeama el 29 de julio de 1888, un día después de la conmemoración de la Proclamación de la Independencia en el Perú, por un estudiante en el contexto de la recaudación de fondos con el fin de rescatar las provincias de Arica y Tacna. Estas fueron tomadas por el ejército chileno después de la guerra de Perú contra Chile que, como se dijo antes, se desarrolló desde 1879 hasta 1883 . El contexto posterior a dicho conflicto bélico generó una atmósfera de desencanto en el Perú de aquellos años. Una de las voces de protesta que llamaba a enjuiciar críticamente el papel de las clases dominantes fue la de González Prada (Rénique, 2016).

La visión organicista, heredera de Spencer, se observa en el siguiente fragmento: "El Perú ha sido el cuerpo vivo, expuesto sobre el mármol de un anfiteatro, para sufrir las amputaciones de cirujanos que tenían ojos con cataratas seniles y manos con temblores de paralítico" (González Prada, 2009, p. 54). En este caso, el Perú, en 1888, es concebido como un organismo biológico que está sobre el mármol, donde se observa el contraste entre lo vivo y lo inerte; pero la crítica esencial de González Prada radica en que la intelectualidad peruana (médicos, abogados, economistas, entre otros) no revelan una especialización en determinada rama del saber. Los científicos son personas improvisadas que no poseen el "saber humilde y silencioso" (González Prada, 2009, p. 54). Por eso, el escritor emplea la metáfora de la enfermedad y desmitifica la labor del cirujano al calificar a este como un ser incompetente, pues no puede visualizar con rigor a su paciente ni está en condiciones de realizar una operación quirúrgica al sufrir de parálisis. Sin embargo, la profundidad de la visión de González Prada va mucho más allá porque la amputación que del Perú hacen los cirujanos alude a la manera como el país se disgregó en diversos grupos humanos que no supieron cohesionarse para enfrentar la guerra contra Chile. El Perú, en consecuencia, es un país amputado, es decir, dividido social y racialmente en grupos enfrentados entre sí porque se desprecia al indígena y hay enfrentamiento entre las diversas clases sociales. ¿Cuál fue la razón por la cual Chile ganó la guerra? González Prada responde de manera rotunda e insiste en la idea del Perú como un cuerpo herido: "La mano brutal de Chile despedazó nuestra carne y machacó nuestros huesos; pero los verdaderos vencedores, las armas del enemigo, fueron nuestra ignorancia y nuestro espíritu de servidumbre" (2009, p. 54). Es decir, la falta de una élite intelectual que buscara la formación de un pensamiento genuino y no imitativo produjo la derrota del Perú frente a Chile: “Anémicos y nerviosos [los peruanos], no sabemos amar ni odiar con firmeza. Versátiles en política, amamos hoy un caudillo hasta sacrificar nuestros derechos en aras de la Dictadura" (González Prada, 2009, p. 56). Por ende, no hay una enraizada tradición democrática en el 
Perú, ya que se rinde culto a los dictadores y no a la libertad individual. Además, González Prada utiliza la metáfora de la enfermedad para fundamentar que los peruanos no han logrado el equilibrio ni en su vida personal ni social, pues no respetan las instituciones democráticas y se amparan en ser siervos de un caudillo. Cabe recordar que el Perú, durante gran parte de su historia, tuvo una sucesión de gobiernos dictatoriales y de golpes de Estado en el siglo XIX, hecho que retrasó el desarrollo de su institucionalidad democrática.

¿Cuál es la solución que plantea González Prada y cómo este emplea la metáfora de la enfermedad? Nuestro autor lo afirma con claridad meridiana:

Nosotros levantemos la voz para enderezar el esqueleto de estas muchedumbres encorvadas, hagamos por oxigenar esta atmósfera viciada con la respiración de tantos organismos enfermos, y lancemos una chispa que inflame en el corazón del pueblo el fuego para amar con firmeza lo que se debe amar, y para odiar con firmeza también lo que se debe odiar (González Prada, 2009, p. 57).

En este caso, observamos la visión antitética entre la vejez y la juventud (Bretoneche Gutiérrez, 2008). González Prada abogaba por la juventud como sinónimo de renovación y de cambio: "¡Los viejos, a la tumba, los niños y los jóvenes a la obra!" (2009, p. 56). Por eso, en el fragmento antes transcrito, se observa la imagen del cuerpo decaído del anciano que se personifica en el esqueleto encorvado de la multitud asociado con la servidumbre, de manera que resulta perentorio producir una transformación corporal (léase: una transformación también en el ámbito de las ideas), pues se trata de enderezar el esqueleto enfermo. En consecuencia, el "nosotros" encarna la labor de un médico que busca realizar una cirugía para curar el cuerpo decaído de la víctima. Además, González fue un crítico despiadado de la corrupción de las clases dominantes en el Perú del siglo XIX y, para ello, emplea la metáfora biológica donde la contaminación (es decir, "la atmósfera viciada") evidencia la enfermedad ética de las clases hegemónicas en aquella época. La idea es que dicha enfermedad se ha propagado como una epidemia moral en el contexto social peruano. La solución de González Prada se fundamenta en un concepto de las ciencias naturales: la combustión. Se trata, sin duda, de producir una chispa que incendie metafóricamente el corazón de las multitudes para que estas puedan asumir, con franqueza y honestidad, sus sentimientos. Así la masa de individuos podrá amar y odiar con rectitud y sindéresis.

En resumen, González Prada señala, en el "Discurso en el Politeama", que la Independencia del Perú fue una farsa porque no significó la formación de una élite intelectual capaz de realizar las transformaciones que el país exigía: "En la orgía de la Época independiente, vuestros antepasados bebieron el vino generoso y dejaron las heces" (González Prada 2009, p. 53). Por ello, la ciencia positiva y la libertad de pensamiento, según González Prada, permitirán a los peruanos alejarse de la 
metafísica y de la teología. De ese modo se podrá superar la enfermedad moral que invade, como una epidemia, los principales ámbitos de la vida social y cultural en el Perú.

\section{EL PERÚ COMO ORGANISMO ENFERMO EN "PROPAGANDA I ATAQUE" (1888)}

Este es uno de los textos donde González Prada se rebela contra la normativa castellana con el fin de acusar de servilismo a los intelectuales peruanos: "Cunde hasta el servilismo internacional: las agrupaciones literarias i científicas tienden a convertirse en academias correspondientes de las reales academias españolas" (2009, p. 93-94). Para ello, plantea una nueva ortografía, pues reemplaza la "y" por la "i", además de emplear el apóstrofo en casos como "s'encuentra" o "s'expresan". Se apoya en la ciencia positiva y cuestiona "el virus teológico, heredado de los españoles" (González Prada, 2009, p. 90). Además, emplea la metáfora animal para caracterizar el catolicismo que representa, en el ámbito físico, "los lagartos voladores de la época secundaria: organismos con alas de pájaro y cuerpo de reptil, seres que hoi vuelan i mañana rastrean" (2009, p. 90).

Veamos el diagnóstico de la enfermedad crónica y generalizada que padece el Perú. En primer lugar, prepondera la fraseología, es decir, el exceso de palabras acompañado por la escasez de ideas: "Carecemos de buenos estilistas, porque no contamos con buenos pensadores, porque el estilo no es más que sangre de las ideas: a organismo raquítico, sangre anémica" (González Prada, 2009, p. 90). En este caso, nuestro pensador establece una relación complementaria entre el plano de la expresión y el del contenido; no obstante, considera que las ideas (el organismo) dan forma (sangre), es decir, forjan el estilo. En segundo término, no existe honradez en el Perú ni en la esfera pública ni privada: "Pueblo, Congreso, Poder Judicial i Gobierno, todo fermenta i despide un enervante olor a mediocridad" (González Prada, 2009, p. 92). Se trata de una crisis institucional generalizada donde los poderes del Estado se hallan capturados por la corrupción. En lo que concierne a las agrupaciones políticas, estas son solo "embriones de partidos con sus hombres i sus credos" (González Prada, 2009, p. 91) porque no poseen individuos que se vuelquen a la acción política, sino que solamente viven, como las tortugas, "acurrucados en el carapacho de su yo" (González Prada, 2009, p. 92). En tal sentido, la parálisis amenaza al Perú y, por ello, González Prada plantea la necesidad de una disección moral para analizar el cadáver y comprobar la lepra que ha padecido cuando fue un cuerpo con vida: "La lepra no se cura escondiéndola con guante blanco" (2009, p. 93).

En consecuencia, la conclusión no deja de ser contundente: "En resumen, hoi el Perú es organismo enfermo: donde se aplica el dedo brota pus" (González Prada, 2009, p. 93). ¿Cuál es la labor del escritor en dicho contexto pleno de desesperanza? Sin 
duda, su rol es de propaganda y ataque. Para cumplir con dicho propósito, debe cumplir la función de periodista y utilizar el folleto para llamar a la conciencia a sus lectores con el fin de que el Perú pueda cambiar de rumbo y tomar la senda correcta. Como se dijo antes, es pertinente, según González Prada, realizar la autopsia al cadáver y dar a conocer la crisis moral generalizada en el Perú después de la guerra con Chile.

\section{CONCLUSIÓN}

Manuel González Prada utiliza la metáfora biológica para trazar un diagnóstico de la sociedad peruana de finales del siglo XIX. Destacan la metáfora de la enfermedad, la animal y la vegetal como procedimientos analógicos para analizar críticamente el Perú como nación donde predominan la crisis ética, la falta de originalidad y la pobreza institucional. En consecuencia, González Prada fue un orador y ensayista que subrayó cómo las clases dominantes, después de la guerra contra Chile, no hicieron esfuerzos por reconstruir el país y siempre vivieron desconociendo el proyecto del Perú como nación heterogénea donde cumple un papel primordial el indígena como eje de la identidad nacional. Influido por las ciencias naturales, González Prada rechazó la teología y abogó por un análisis minucioso de los males de la sociedad peruana para que esta pueda, en el futuro, enrumbar su camino y enmendar sus errores históricos. Por eso, la obra de nuestro autor mantiene su eficacia y vigencia en el ámbito del pensamiento político y de la literatura en Latinoamérica. 


\section{BIBLIOGRAFÍA}

Bachelard, G. (1992). L'Air et les songes: essai sur l'imagination du mouvement. Paris: le Livre de Poche.

Bretoneche Gutiérrez, L. A. (2008). La concepción del hombre en el pensamiento de Manuel González Prada (Tesis para obtener el título de Licenciado en Filosofía). Lima: Universidad Nacional Mayor de San Marcos.

Calderón de la Barca, P. (2018). El gran teatro del mundo. México D.F.: Fondo de Cultura Económica.

Fernández Cozman, C. (2005). La soledad de la página en blanco. Ensayos sobre lírica peruana contemporánea. Lima: Fondo Editorial de la Facultad de Letras y Ciencias Humanas.

García-Bedoya Maguiña, C. (2004). Para una periodización de la literatura peruana. 2 ed. corregida y ampliada. Lima: Fondo Editorial de la Universidad Nacional Mayor de San Marcos.

García Salvatecci, H. (1972). El pensamiento de González Prada. Lima: Arica.

García Salvatecci, H. (1990). Visión de un apóstol. Pensamiento del Maestro González Prada. Lima: Emisa.

González Prada, M. (2009). Ensayos escogidos 1885-1916. Ed. I. Tauzin-Castellanos. Lima: Universidad Ricardo Palma.

Gónzalez Prada, M. (2015). Ensayos y poesía. http://evergreen.loyola.edu/tward/www/gp/

Greimas, A. J. (1987). Semántica estructural: investigación metodológica. Madrid: Gredos.

Lakoff, G. \& Johnson, M. (2003). Metaphors We Live By. Chicago \& London: The University of Chicago Press.

Lakoff, G. \& Turner, M. (1989). More than Cool Reason. A Field Guide to Poetic Metaphor. Chicago \& London: The University of Chicago Press.

Lino Salvador, L. E. (2013). El ritmo y la modernización de la lírica peruana. Los casos de González Prada, Eguren y Valdelomar. Lima: Universidad San Ignacio de Loyola.

Perelman, Ch. \& Olbrechst-Tyteca, L. (1989). Tratado de la argumentación. La nueva retórica. Madrid: Gredos.

Podestá, B. (1975). El pensamiento político de Manuel González Prada. Lima: Instituto Nacional de Cultura.

Quintanilla, P. (2006). La recepción del positivismo en América Latina. Logos latinoamericano, 6, $65-76$

Rénique, J. L. (2016). Imaginar la nación. Viajes en busca del "verdadero Perú” (1881-1932). Lima: Instituto de Estudios Peruanos.

Riva Agüero, J. de la (1962). Carácter de la literatura del Perú independiente. In Obras completas. T. 1. Lima: Pontificia Universidad Católica del Perú.

Sánchez, L. A. (1975). La literatura peruana. Derrotero para una historia cultural del Perú. Lima: P.L. Villanueva Editor.

Sobrevilla, D. (2005). El marxismo de Mariátegui y su aplicación a los 7 ensayos. Lima: Universidad de Lima.

Sobrevilla, D. (2012). Escritos mariateguianos. Artículos y reseñas en torno a José Carlos Mariátegui y su obra. Lima: Fondo Editorial de la Universidad Inca Garcilaso de la Vega.

Spencer, H. (2017). Filosofia do estilo. Goiânia: Cânone Editoração.

Tauzin-Castellanos, I. (Ed.) (2006). Manuel González Prada: escritor de dos mundos. Lima: IFEA-Embajada de Francia \& BNP-PUB.

Tauzin-Castellanos, I. (2009). Introducción. In M. González Prada, Ensayos 1885-1916 (pp. XIIIXIV). Lima: Universidad Ricardo Palma.

Ward, T. (2001). La anarquía inmanentista de Manuel González Prada. Lima: Ricardo Palma \& Editorial Horizonte. 